\title{
Sexuality After Hysterectomy: A Qualitative Study on Women's Sexual Experience After Hysterectomy
}

\author{
Fatemeh Shirinkam ${ }^{1}$, Zahra Jannat-Alipoor ${ }^{1}$, Roghieh Shirinkam Chavari $^{2}$, Fatemeh Ghaffari ${ }^{*}$
}

\begin{abstract}
Objectives: This study was done to explore the sexual experience of women after hysterectomy.

Materials and Methods: This is a qualitative study done by the use of content analysis method. The research community includes women with the experience of hysterectomy who were admitted to the treatment centers or private clinics in the west of Mazandaran province, Iran in 2016. Purposeful sampling was applied and the single face-to-face interview with 20 participants was the method for data gathering. Interview guide was used as the research tool; then the interviews were analyzed according to the Granheim and Lundman method.

Results: The data has been classified into 4 main categories of "hysterectomy as a decaying or renewing process in sexual relationship", "sexual ability with no womb", "limitations of seeking help" and "perceiving the need for comprehensive supports".

Conclusion: Psychological interviews for exploring the fear of sexual behavior and consulting with peer groups or psychological consultation for couples before hysterectomy can help in clarifying the surgery side-effects and decreasing the fear. Mental and economical support from family members, following the treatment up and advanced supports like exploring sexual needs, screening the problems, educating couples on sexual affairs and rebuilding the self-image can be helpful in creating a stress-free sexual life for this group; besides, presenting treatment solutions like vaginoplasty or on time appropriate treatment of sexual problems is also recommended.

Keywords: Hysterectomy, Sexual behavior, Qualitative study
\end{abstract}

\section{Introduction}

Hysterectomy after caesarian section is amongst the most prevalent women surgeries worldwide; and it is estimated that $45 \%$ of women under 65 years of age have experienced this surgery (1).

The number of hysterectomy surgeries before the age of natural menopause has increased during the recent years, the reason for which in most of the cases is the presence of benign tumors inside the women's genital organ. This surgery can result in mental and physical disorders in women, specially the hysterectomy before the natural menopause which stops the menstruation, and more fierce mental problems (2). Studies show that most of the women who have experienced hysterectomy are concerned about the change in their sexual situation and being rejected by their husbands in such a situation (3-5) and most of them believe that this surgery destroy their womanliness, decreases their sexual desire, makes their husband or partner reject them and increases the couples' problems. Cultural beliefs are another effective factor in which getting to the menopause age is known as a senility symptom and sexual inability sign among the societies (6). Numerous studies have proven the long or short-time sexual relationship disorders after hysterectomy $(4,7)$.
The prevalence of such disorders is reported from $10 \%$ to $40 \%$ in different researches $(8,9)$. Painful intercourse, vaginal dryness, loss of the sexual tendency or decrease in it, involuntary vaginal contractions, decrease in sexual sensitivity, pain, decrease in orgasm satisfaction or getting orgasm are among the sexual consequences (6). However, change in mental image and self-confidence, fierce emotional sensitivity and depression are known as the psychological ones $(4,7)$.

Merighi et al believe that women's experience, expectations and the assumption about hysterectomy surgery are influenced by their beliefs, concepts, opinions and personal life values; therefore, exploring their experiences and opinions after hysterectomy can be useful in matching the caring activities with their needs (10). Doing exploring researches on the sexual challenges of women after hysterectomy can clarify the problems and help in finding suitable solutions by taking into account the fact of the high prevalence of this surgery and its psychological consequences influencing both the individual and family life. Meanwhile, sexual affairs are known as the most important couple issues and satisfying sexual relationships are among the factors affecting the satisfaction and health level of a family (11). Therefore

Received 5 November 2016, Accepted 14 March 2017, Available online 10 April 2017

${ }^{1}$ Ramsar Nursing Care Research Center, Health Research Institute, Babol University of Medical Sciences, Babol, Iran. ${ }^{2}$ Guilan University of Medical Sciences, Rasht, Iran.

*Corresponding Author: Fatemeh Ghaffari, Tel: +989024801001, Email: ghafarifateme@yahoo.com 
the current study was conducted to explore the sexual experience of women after hysterectomy.

\section{Materials and Methods}

Design

This is a qualitative study resulted by conventional content analysis.

\section{Selection}

The research population includes women with a history of hysterectomy who were admitted to the treatment centers or private clinics in the west of Mazandaran province, Iran in 2016. In this study, purposeful sampling in which the participants are selected with the highest variety of age, the time spend after hysterectomy, education level, number of children, hysterectomy type, hysterectomy reason and so on is used.

\section{Data Collection}

Semi-structural face-to-face individual interviews were used for data gathering. The interview started with a general question like: "would you please share your experience of sexual function after hysterectomy with us?" and it was continued with probing ones to have a deeper perception of the phenomenon. The time of each interview varied between 30 to 45 minutes according to the participant's tolerance and their tendency to share their experiences, feelings and perceptions of the phenomenon. The participant reached an agreement with the researcher before the interview about the time and the place whether gynecology clinic or their own home was suitable for this purpose. All the face-to-face interviews were held in a calm and private place to keep the personal privacy. All the participants were interviewed once, so 20 interviews were conducted. The main criteria for selecting the participants included having 6 months experience of living after abdominal hysterectomy, being married, not having vaginal cancers and their tendency to share their experience with the researcher. Interviews were recorded by a digital recorder and were continued up to data saturation.

\section{Analysis}

The data was analyzed by continuous comparison and conventional content analyses (12). The content analysis is a research method for mental interpretation of transcribed data contents. Systematic categorizing, codes and themes are explored in this method. The data analysis was done continuously and at the same time with data gathering. Verbal transcription of interviews was reviewed numerously. In vivo coding was used for initial coding of participants' words and then the next interviews were held. Meaning units have been extracted from participants' statements which formed the initial codes or open codes. The codes were reviewed numerously and categorized according to the similarity and proportionality of the subject. Then, the categorizing is formed by separate codes, frequent review and merging similar codes. Thus, the second level coding went on. Categories were compared, the vast categories appeared by incorporating the similar ones in the next level and finally themes were extracted. Final categories and initial text were reviewed to get an agreement between the researcher and participants about the meaning of each category. The researcher tried not to enter her assumption into data analysis.

\section{Data trustworthiness}

The 4 criteria of credibility, transferability, dependability and conformability were used to evaluate the accuracy of the data (13).

Member checking was used to check the credibility. We incorporated a variety of data gathering methods (interviews and field notes) in this study. The highest variety was applied in sample selection. A peer checker familiar with qualitative study also cooperated in data checking to get an agreement about research process and findings. All the activities has been recorded carefully and to check the transferability of the gathered data, two of the women who experienced hysterectomy with similar problems but out of our participants were requested to review and confirm the data.

\section{Results}

The average age of participants was 48.75 years. Other demographic information is presented in Table 1.

Four main categories emerged from the data and 2 to 4 distinctive subcategories within each category were identified. These categories and their subcategories are shown in Table 2.

Hysterectomy as a Decaying or Renewing Process in Sexual Relationship

The women's sexual experience after hysterectomy is like spectrum expanded from disgust, decrease or cut of sexual relationships to obtaining pleasure and increase in sexual relationships. This category is made up of "fear as an affecting factor in sexual relationships", "run away from sexual relationships" and "treating the imperfect sexual relationships".

\section{Fear as an Affecting Factor in Sexual Relationships}

The women who experienced hysterectomy have a life full of fear and concerns. The fear of physical damage is prevalent in the early stages after the surgery. This group of women can induce the fear in their mates, which may result in frustration, not getting sexually satisfied and finally cut or decrease in sexual relationships. On the other hand, they can delay the decision for the surgery among hysterectomy candidates by inducing fear in them. "Just fear is annoying; otherwise I haven't felt anything during these 6 years. I was just afraid of getting harmed ... I was afraid of bleeding, infection and previous 
Table 1. Demographic Information of the Participants With a History of Hysterectomy

\begin{tabular}{|c|c|c|c|c|c|c|c|}
\hline Code & Age (y) & Education Level & Job/Occupation & Type of Hysterectomy & Reason of Hysterectomy & $\begin{array}{l}\text { Time Passed After } \\
\text { Hysterectomy (y) }\end{array}$ & $\begin{array}{l}\text { No. of } \\
\text { Children }\end{array}$ \\
\hline 1 & 45 & Primary school & Housewife & Hysterectomy & Menorrhagia & 2 & 3 \\
\hline 2 & 36 & High school & Housewife & Hysterectomy & Menorrhagia/adenomyosis & 3 & 1 \\
\hline 3 & 48 & Primary school & Housewife & $\begin{array}{l}\text { Hysterectomy and bilateral } \\
\text { oophorectomy }\end{array}$ & Menorrhagia/ uterine hypertrophy & 2.5 & 3 \\
\hline 4 & 51 & Graduated & Employee & Hysterectomy & Fibroids & 6 & 2 \\
\hline 5 & 48 & High school & Housewife & $\begin{array}{l}\text { Hysterectomy and unilateral } \\
\text { oophorectomy }\end{array}$ & Menorrhagia/ uterine hypertrophy & 2 & 2 \\
\hline 6 & 43 & Primary school & Housewife & Hysterectomy & Uterine hypertrophy/ Fibroids & 2 & 3 \\
\hline 7 & 40 & Primary school & Housewife & Hysterectomy & $\begin{array}{l}\text { Uterine hypertrophy/ Fibroids/ } \\
\text { menorrhagia }\end{array}$ & 1.5 & 2 \\
\hline 8 & 44 & Primary school & Housewife & Hysterectomy & Menorrhagia/fibroids & 2.5 & 2 \\
\hline 9 & 42 & Graduated & Employee & $\begin{array}{l}\text { Hysterectomy and unilateral } \\
\text { oophorectomy }\end{array}$ & Menorrhagia & 4 & 1 \\
\hline 10 & 47 & MSc graduated & Employee & $\begin{array}{l}\text { Hysterectomy and bilateral } \\
\text { oophorectomy }\end{array}$ & Uterine hypertrophy/ Fibroids & 3 & 2 \\
\hline 11 & 46 & High school & Housewife & Hysterectomy & Menorrhagia & 5 & 1 \\
\hline 12 & 38 & MSc graduated & Employee & Hysterectomy & Fibroids & 2 & 1 \\
\hline 13 & 49 & High school & Housewife & Hysterectomy & Menorrhagia & 3 & 1 \\
\hline 14 & 53 & Graduated & Employee & $\begin{array}{l}\text { Hysterectomy and bilateral } \\
\text { oophorectomy }\end{array}$ & Fibroids/menorrhagia & 5 & 3 \\
\hline 15 & 50 & High school & Housewife & Hysterectomy & Fibroids & 3.5 & 2 \\
\hline 16 & 43 & Graduated & Employee & Hysterectomy & Menorrhagia & 1 & 2 \\
\hline 17 & 47 & MSc graduated & Employee & $\begin{array}{l}\text { Hysterectomy and bilateral } \\
\text { oophorectomy }\end{array}$ & Menorrhagia & 1.5 & 1 \\
\hline 18 & 56 & MSc graduated & Employee & Hysterectomy & Fibroids/menorrhagia & 5 & 2 \\
\hline 19 & 48 & Graduated & Housewife & Hysterectomy & Menorrhagia & 2 & 1 \\
\hline 20 & 54 & Graduated & Employee & Hysterectomy & Menorrhagia/ uterine hypertrophy & 4 & 2 \\
\hline
\end{tabular}

Table 2. Main Categories and Subcategories

\begin{tabular}{ll}
\hline Categories & Subcategories \\
\hline Hysterectomy as a decaying or procreator process for sexual relationship & Fear as an affecting factor in sexual relationships \\
& Run away from sexual relationships \\
& Treating the imperfect sexual relationships \\
\hline Sexual ability with no womb & The feeling of early sexual breakdown \\
& Feeling guilty \\
& Ambiguous sense of womanliness \\
& The lack of womb \\
\hline Limitations for searching help & Sexual ignorance \\
& Preventing to get ridiculed \\
\hline Need for comprehensive support & Feeling ashamed \\
\hline & Understanding the situation and compromising \\
\end{tabular}

problems to happen again (code 6)."

"My husband said 'I am afraid of harming you by sex' earlier. He was afraid of getting close to me; he was afraid of causing a problem. He stopped the intercourse whenever I felt pain (code 1)."

The fear of facing with others' chiding, especially from the treatment team and receiving negative reactions from the husband and getting rejected are among the effective factors in sexual relationships as our participants believe.
This group of clients use coping solutions like pretending to have orgasm in this case. Using this mechanism can end in disappointment, decrease in self-confidence and feeling valueless in women who experienced hysterectomy.

"Whenever my husband comes and requests for sex, I feel disgusted and I say oh! He came to have sex and laugh at my vagina which is like a balloon. That's why I don't like him to get close to me (code 6)."

"My husband asked about whether I got an orgasm or 
not during the sex. I wasn't pleased but I responded yes. It was because of getting rid of blaming. He said how do you feel? And I responded good! But I didn't feel anything actually. I didn't wish for sex but I showed enthusiasm and I didn't reject the intercourse and cooperated in order not to induce the feeling coldness (code 7,5,3).

"The place of surgery was OK but I felt pain internally. I was afraid that something would happen; something like infection or bleeding. Then what do I have to tell the doctor about the reason of such problems? She would understand the reason which was intercourse and I lose my reputation. I thought about these things and so I didn't let my husband have sex with me (code 8).

\section{Run Away From Sexual Relationship}

The other problem women with hysterectomy experience faced was decrease in tendency to have sexual relationships. These people started to make excuses to get rid of sexual relationships due to their frigidity. They try to arise the feeling of pity or sin in their husband by enlarging the problems and talking about the probable harms made by sex.

"I feel nothing when my husband comes to me. I can't. I don't like it. I've told him that I cannot tolerate the intercourse, I get ill and exhausted; that's why it's hard for me. He felt pity and coped earlier (code 3)."

The important fact is that cutting the number of sexual intercourses or seeing the displeasure of woman and facing with physical problem complaints after the relationship can end in psychological reactions in men like anger, aggression and suppression of eroticism. As participants believe, sexual relationship is a way of showing the feelings and feeling safe for the couple; however, facing with man's dissatisfaction from sexual relationship can cause frustration and humility in women. Some of the participants talked about their eroticism even after the hysterectomy but they faced with change in man's viewpoint regarding his wife as a sex mate.

"We're not like before. We don't feel like then because my husband is complaining and I get upset. I feel uneasy when he looks at me. He feels pity for me now and he says that his previous intercourses were great but now he doesn't like it. I cannot be what he wants and he looks at me in an agonizing manner after the sex and it's obvious that he is not satisfied (code 6)."

\section{Treating the Imperfect Sexual Relationships}

Despite having a negative mind about the effects of hysterectomy on sexual satisfaction, some of the participants know it as an improvement factor in sexual quality due to getting free from earlier problems like pain, bleeding, fear of unwanted pregnancy and contraceptive pills.

"Having 10day bleeding per month, anemia, anxiety and insomnia while I couldn't accept my husband for sex in numbers, it's better now. I had a lot of pain and bleeding then but now it is OK (code 5)."

"Sexual intercourse was painful before the surgery but now I don't feel pain anymore. I wasn't convenient then but now I'm comfortable (code 1)."

Sexual Ability With no Womb

This category contains four subcategories including: "the feeling of early sexual breakdown", "feeling guilty", "ambiguous sense of womanliness" and "the lack of womb".

\section{The Feeling of Early Sexual Breakdown}

Participants believe that the change in husband's attitude and the decrease in his sexual desire besides the change in self-image, decrease in sexual desire, dryness of vagina and mental behaviors following the surgery can result in the loss of both physical and mental incitement; therefore, the decrease in sexual satisfaction, quantity and quality of sexual intercourses and feeling early sexual break down happens in them.

"I always try to be quiet since I know I am seared in sexual issues. I try to accept his sexual requests because now I am incomplete without womb. It's all I can do for him (code 8)."

"The surgery affects the sexual ability badly! I don't feel the sexual intercourse as I did before. I liked the orgasm but not now I don't. I get anxious fast while I got an orgasm and made it for him before, but not now ... it's a horrible experience and it's not good at all. I'm upset about the life. I have to do it but I don't like. I think I can never enjoy the sex anymore (code 6)."

\section{Feeling Guilty}

Some of the clients suffered from feeling guilty about getting frigid and the lack of tendency for sex. They preferred tolerating problems like bleeding or the ones related to the diagnoses of womb-related illnesses but had no problem in sexual relationships with their mate. This was experienced more in women whose ovaries were extracted. Their social and family relationships were influenced by the preoccupation made by sexual disorders. Feeling ashamed, regretful, anxiety, depression and social isolation are among the problems they experience after hysterectomy. Some use the solutions like assigning their states and belongings their husbands or permitting remarriage. Feeling guilty can result in unwanted sexual intercourse. Couples try to put their mate's needs as the priority rather than their own needs due to different reasons.

"I am ashamed of my disability in giving a good orgasm to my husband. I feel ashamed when I look at him after sex and I get regretful. He became tired earlier and said: why did you do that (surgery)? I wish there was no surgery (code 6)."

\section{Ambiguous Sense of Womanliness}

Decrease in self-confidence, loss of an important body 
organ which makes the difference between man and woman and decrease in appearance adornment because of being involved with treatment problems and the decrease in future hope create an ambiguous sense of womanliness in women who experienced hysterectomy. Husbands help in the creation of such a feeling on the other hand. Weakening the feminine aspect of life is done by the husband through expressing their sexual dissatisfaction, woman's disability in pregnancy and mate's mind as an incomplete human.

"... My husband complains about the sexual relationship. I think it's because of the womb that I don't have. I don't have the earlier womanliness. I am not attractive to him anymore. I feel asthenic and I'm not like other women (code 6)."

\section{The Lack of Womb}

Since the womb has an important mental role in tendency for sexual relationship, the negative self-image created by the lack of this organ can result in reactions like husband's separation, segregating the bed, excusing for not having sex, aggression and depression. The important fact in data is that the husband feels the lack of womb during the sex and can induce it in his wife. Not having orgasm can make the mate use insanitary solutions which is followed by mental damages due to religious or sanitary beliefs.

"I feel the lack of womb completely during the sex ... I feel the deficiency in comparison with other women since the womb is so important. I felt special before the menstruation (depression and sadness) and it disappeared after it; but there is nothing now and I feel vacuity during the intercourse (it seems that there is nothing in my body and it's empty). I think my husband doesn't enjoy like then. He likes to get close to me (for sex) but I feel he doesn't enjoy like what he did before... it's hard to say. He uses other solutions and it makes me sad. I feel guilty. I don't like it. When I don't let him, he insults; I mean he speaks irreverently because he doesn't like to see any resistance and he wants me to be always quiet (code 7)."

\section{Limitations of Seeking Help}

This category contains 3 subcategories including: "Sexual ignorance", "Avoiding getting ridiculed" and "Feeling ashamed".

\section{Sexual Ignorance}

Some of the participants do not tend to refer to professional people or receive medical consultation because of different reasons like not feeling the need for receiving such helps. Thus, their information on sex and how to behave sexually is very limited. Most of them consult with unprofessional people and, therefore, do dangerous sexual behaviors like oral and anal sex.

"I don't need to refer to doctor for sexual problems. There is no need to be always concerned about these issues.
My friends have given me some information and that's enough (code 9)."

\section{Avoiding getting ridiculed}

Since the women who experienced hysterectomy perceived the extraction of womb as a defect, avoid requesting help to confront against the sexual problems with their husband and express their feelings in order not to get ridiculed by others. They actually feel the need to receive help but do not act due to their concern about getting ridiculed.

"The doctor would ridicule me if I say I've gotten frigid and I don't like the intercourse while I have three children. It's not good to talk with the doctor about sexual problems. It's wrong ... but I tell my sister to go since she's so frigid like me and I tell her to go and ask and don't be like me. I guide them to go to doctor and do not postpone it (code 3)."

\section{Feeling Ashamed}

The negative cultural viewpoint of the society makes the clients not talk about the genital or sexual relationship problems with others as the participants believe. Even most of them know feeling ashamed as the main reason for not receiving professional consultation.

"I feel ashamed. I always think about others who would say that a mature woman is talking about these issues. It was hard ... I think it's not good to talk about sex and the related problems in this age (code 3)."

"Honestly my husband and I do not talk about sex and both of us are ashamed. Once I asked and he said that the orgasm is not like before. He has proven this by anal sex... I liked to talk with someone but it was shameful. Sexual issues are important and I don't like to talk with anybody but at least an informed person (code 7)."

\section{Need for Comprehensive Support}

Women with hysterectomy experience need comprehensive support from their family and specially their husband and professional people during the follow-up period of their illness, passing through the treatment process, protecting their marriage and increasing the hope to create a successful marriage specially in sex. This category contains 2 subcategories including: "Understanding the situation and compromising", and "Receiving professional support”.

\section{Understanding the Situation and Compromising}

Women with hysterectomy experience live with the stress of diagnosis, treatment and medical follow -ups. The fear of losing their marriage, husband's kindness and attention causes numerous problems to them. Therefore, understanding their situation by their mate is the only request. Empathy but not the compassion among the family members results in a better adaptability with different hysterectomy problems and makes them have a 
more efficient sexual relationship; They feel satisfied and attempt to rebuild the sexual problems after hysterectomy. Some of them expect their husband to understand their sexual needs.

"I felt absurdity before but it became normal. When I saw my husband's reactions it became normal. He said it's your own body and we don't need a child anymore; these two children are enough. That's why it became normal. His words were so effective. He tolerated a lot and had my back when he couldn't have sex before the surgery when I had bleeding. He continued for the next 6 months after the surgery and didn't request for sex (code 2)."

"You know, my husband thinks that I should be ready (for sex) whenever he wants. I have requested him to understand me a lot and he wants me to understand him in return. 2 or 3 months after the surgery he needed to have sex frequently and I was under pressure, depressed and sad. I decided to separate when he didn't behave friendly. It seemed that he was living with a stranger. When the doctor (psychiatrist) came to our neighborhood health center I called her and talked. It made me calm (code 8)."

\section{Receiving Professional Support}

Most of the participants believed that receiving sexual education and emotional support from professional people like doctors and nurses can help them have an efficient sexual relationship. However, they cannot use the supportive services in the society after the hysterectomy because of not putting enough time for sexual education.

"They had not told me about sexual issues. Our doctors do not share enough information unfortunately. They just got his satisfaction and signature for the surgery and they told that the womb will be extracted. He was so sad and concerned (code 7)."

Most of the participants believe that financial problems and the cost of services are among the main reasons for not using the diagnosis, treatment and consulting services about sex.

"A doctor's visit is so costly and the clinic is crowded. That's why I don't refer and I don't like to pay. I don't like to get treated ... if everything was fine (financially) I may have gone; since it's necessary to find a solution for these problems (getting clod in sexual problems). Since I feel that I need my husband and I want to be like before sometimes ... I told him that there's a reconstructive surgery and it can help. He said you can go, there is no problem but when I said that it's costly, he became silent (code 6)."

\section{Discussion}

The results of this study show that one of the main problems of sexual relationship in women who experienced hysterectomy is fear. This group of women were afraid of sexual relationship and induce it in their husbands for not experiencing previous problems like pain or bleeding anymore. Researches show that the decrease in sexual desire, number of intercourses and finally the sexual satisfaction are all created by fear (14). The results of previous studies show that no satisfying sexual relationship will result in anxiety, inability to do daily tasks, problems in mental focusing, disorder in social activities and free time, change in sleeping pattern, moodiness, decrease in communication and decrease in couple life quality $(11,15)$.

The results of this study show that the fear of facing with negative reactions of husband makes them use the solutions such as getting far or running away from sexual relationships. Wang et al mention the relationship of sexual dysfunction of women with breast cancer. Nearly half of the reported cases in his study refused the sexual intercourse and experienced it once or twice a year while $90 \%$ of his participants reported a meaningful decrease in their sexual activities (16).

This fact can raise feeling of despair and mutual refusal in the mates over a long period of time. The results of other studies show that the women may not be able to do their marital duties and get psychological disorders like depression, anxiety and decrease in self-confidence $(14,17,18)$. After hysterectomy, they were concerned about getting rejected by their husband $(6,14)$ and feel like losing their womanliness $(17,18)$. Since the recovery after the surgery is gradual and includes the mental and physical aspects, at least 12 months of follow up is needed to check the hysterectomy effects on sexual relationships (19). Some of the participants believe that sexual satisfaction of both women and their husbands is increased while some believe that the hysterectomy is a factor in the decrease of sexual tendency and satisfaction. Satisfied ones tend more to have sex due to the removal of obstacles like bleeding and pain (20-24). The results of Merighi et al also showed that hysterectomy was a factor improving the relationships including the sexual ones (10). On the other hand, some other studies state no change (25) or decrease in sexual ability after hysterectomy (26).

The results of the current study show that the feeling of absurdity created by the lack of womb is amongst the problems which disturb the sexual ability. Since women know the womb as the main feminine organ, its lack is a loss due to change in their self-image (27). The results of Merighi et al highlighted that the woman's perception of hysterectomy is influenced by social and cultural inductions; in a way that lack of womb makes the feeling of the presence of a cavity in body as a defect which is known as a threat for losing the husband and a destroyer of marriage (10). Researches show that the husbands may face with the decrease in sexual desire and change in attitude toward their wife after hysterectomy (18). They may have negative reactions like aggression, separation and disloyalty. Psychiatric interventions before the surgery can affect the anxiety, stress and depression, insolvency and surgery consequences in couples (28). The results of this 
study show that some of the women feel guilty of decrease in sexual desire and inability in giving sexual satisfaction to their mate even if some of them have experienced the hysterectomy due to medical reasons. The feel of being guilty and mental contentions disturbs their sexual ability (29). They use reparative mechanisms like anal or rectal sex in order to increase their husband's sexual satisfaction which sometimes can result in numerous physical and mental problems like infection in vaginal organs and catching venereal diseases both in them and their husband (30). Besides, using such solutions is in conflict with Iranian women's religious beliefs and can have consequences like regarding oneself as a sinner (31). The results also show that the feeling of being guilty can cause sexual canniness in women or their husband while both of them see themselves responsible for meeting their mate's needs even when they have low sexual desire. The participants of a study conducted by Khajehaminian et al believed that the canniness created by the wives of men who experienced mastectomy is applied due to patient's physical weakness or threatening the sexual relationship as a threatening factor for health while the canniness applied by the patient is because of concerns about liaison and respecting her needs (32).

The research done by Kagawa-Singer et al showed that Asian women are more worried about the family while the European or American ones are more worried about the sexual intimacy with their husband. They have also found that the men know sex request as a careless behavior after breast cancer diagnosis (33). Our results show that women feel ambiguous about their womanliness due to lack of the womb which can decrease their sexual ability. The womanliness is defined based on different aspects of being a wife and having a baby while the lack of womb conflicts with their roles as a woman $(10,34)$. As the womb is an important part of woman's self-image and sexual selfimage, some of them are afraid of losing their feminine attractiveness to their mate after the surgery (35). These clients do not try to increase their feminine attractiveness due to change in their self-image which can result in less sexual tendency in their mate $(36,37)$. Merighi et al believes that reproduction is a common sense which is related not only to the sexual relationship but also to the genital organs; so lack of womb results in no reproduction and decrease or destruction in sexual desire in some cases. This can provoke the belief of getting frigid after hysterectomy among women (10). The results indicate that the tendency to receive sexual information is turned into shame due to the lack of general sexual knowledge, not believing the role of sexual relationship in mental health and family health and the cultural beliefs among Iranian women; so talking about sexual problems and receiving consultation are ignored. It guides the clients to unprofessional people which result in receiving wrong information. They do not talk about sexual problems with professional people in order to avoid getting ridiculed.
Facing with such problems decreases the help request from professional people (38). Besides, these people feel lonely due to not receiving sympathy from others. The results of study by Merighi et al showed that their participants had a positive experience of hysterectomy. This can be due to their participation in educational programs in ambiguity resolving, decreasing the anxiety related to the surgery and receiving self-care and consultations about the correction of false beliefs (10). The results show that women with hysterectomy experience need professional help and family support, specially from their husband, to increase the quality of their sexual life after the surgery. They feel the threat of losing their marriage due to the decrease in their sexual ability. Understanding the situation by the mate and showing sympathy can result in more hope, self-confidence and attempt to rebuild the sexual life $(39,40)$. This group of clients know the mate's emotional support as an important factor in treatment follow-up (41). As the emotional and mental aspects of sex and the feeling of safety in sexual relationships are known quite important, facing with husband's negative reactions like blame, not having sex, sex abhorrence and so on can cause anxiety, frustration and feeling of being useless in woman. The importance of extracting the womb is much more compared with other abdominal organs; especially for those who are at fertility levels. These people should compromise with the absence of menstruation and inability in reproduction. It is necessary to inform both the clients and their family members besides providing appropriate mental support and consultation for women who would experience the hysterectomy in order to make the situation compromising (42). The women participated in a study by Merighi et al were also trying to improve quality of their life in order to have a healthy life and become strong against daily issues (10). Researches point to the importance of informing and cognitive deal before the surgery in increasing the patient's general satisfaction, decreasing her anxiety, accelerating the physical recovery and increasing the psychological adjustment. It's been proven that interventions like informing the patient candidate for hysterectomy and providing them with mental and social support results in positive effects on surgery consequences. Researchers believe that the doctor and the nurse should educate the patient and specially her husband in order to prevent the following sexual problems after the hysterectomy $(43,44)$.

\section{Conclusion}

The results of this study show that fear is among the effective factors in sexual relationship of couples. Psychological interviews can help in exploring the fear from sexual behaviors and consulting with peer group beside psychological consultation in both the patient and her husband before the hysterectomy can clarify the surgery's side-effects and decrease the fear. The other important factor is the lack of womb which affects the 
sexual ability by creating the feeling of being guilty and feeling ambiguous about womanliness; therefore, consulting with specialist doctors and psychologists before the surgery and using treatment solutions like vaginoplasty or other on time treatments of sexual problem are recommended to the couples. It is needed to provide comprehensive supports by the family members through financial supports in treatment follow up and not applying mental pressures besides the support by the professional people in exploring the sexual needs, screening the sexual problems, educating couples on sexual issues, changing the attitude and rebuilding the self-image in order to help this group of women in experiencing a stress-free sexual life. It is recommended that the role of body-image in sexual ethology, psychotherapy and health consultation in treatment, supportive and relief care of women who experienced hysterectomy be taken into account in holistic planning.

\section{Conflict of Interests}

Authors declare that there is no conflict of interest.

\section{Ethical Considerations}

An introduction letter was taken from Babol University of Medical Sciences. All the women who participated in this study have the experience of hysterectomy, and were aware of the research aims and the interviews were recorded with their written consent. They were assured about the secrecy of their information and they could have the recorded file and get informed about the final results if they wanted. They were also informed about the right of discontinuing the process; however, none of them left the study. The study protocol of this research was approved by Babol University of Medical Sciences, No UBABOL. REC.2015.157.

\section{Acknowledgment}

Researchers express their gratitude and appreciation to all participants in the study.

\section{References}

1. Banu NS, Manyonda IT. Alternative medical and surgical options to hysterectomy. Best Pract Res Clin Obstet Gynaecol. 2005;19(3):431-449. doi:10.1016/j. bpobgyn.2005.01.006

2. Jelovsek JE, Barber MD. Women seeking treatment for advanced pelvic organ prolapse have decreased body image and quality of life. Am J Obstet Gynecol. 2006;194(5):14551461. doi:10.1016/j.ajog.2006.01.060

3. Babazadeh R, Mirzaeei KH, Akhlaghi F. Sexuality after Hysterectomy (A Systematic Review). Iranian Journal of Obstetrics Gynecology and Infertility. 2012;14(7):51-68.

4. Ghanbari S, D. PS. Comparison of sexual satisfaction after total and subtotal abdominal hysterectomy. J Fac Med Tehran Uni Med Sci. 2007;65(9):31-35.

5. Zobbe V, Gimbel H, Andersen BM, et al. Sexuality after total vs. subtotal hysterectomy. Acta Obstet Gynecol Scand.
2004;83(2):191-196. doi:10.1111/j.0001-6349.2004.00311.x

6. Nosrait M, Rahmani AR, Naghibi FS, Razavi A. A study on the effects of education on marital life satisfaction of women undergone hysterectomy in Urmia chosen hospitals,1386. J Urmia Nurs Midwifery Fac. 2007;5(3):129-136.

7. Rannestad T. Hysterectomy: effects on quality of life and psychological aspects. Best Pract Res Clin Obstet Gynaecol. 2005;19(3):419-430. doi:10.1016/j.bpobgyn.2005.01.007

8. Badakhsh MH, Taftachi F, Mehrabi F, Derakhshan A. The Effect of Hysterectomy in Securing Sexual Desire and Satisfaction. Iranian Journal of Surgery. 2009;17(1).

9. Lonnee-Hoffmann R, Pinas I. Effects of Hysterectomy on Sexual Function. Curr Sex Health Rep. 2014;6(4):244-251. doi:10.1007/s11930-014-0029-3

10. Merighi MAB, de Oliveira DM, de Jesus MC, Hoga LAK, de Oliveira Pedroso AG. Experiences and expectations of women submitted to hysterectomy. Texto ContextoEnfermagem. 2012;21(3):608-615. doi:10.1590/S010407072012000300016

11. Ebrahimipour $\mathrm{H}$, jalambadani $\mathrm{z}$, vafaee najjar a. the first Experience of Sexual Relations in Married Women in Sabzevar - a phenomenological Study. Iranian Journal of Obstetrics Gynecology and Infertility. 2012;15(4):1-11.

12. Graneheim UH, Lundman B. Qualitative content analysis in nursing research: concepts, procedures and measures to achieve trustworthiness. Nurse Educ Today. 2004;24(2):105112. doi:10.1016/j.nedt.2003.10.001

13. Polit DF. Essentials of Nursing Research: Appraising Evidence for Nursing Practice. Lippincott Williams Wilkins; 2013.

14. Gueye M, Diouf AA, Cisse A, Coulbary AS, Moreau JC, Diouf A. [Consequences of hysterectomy at the nationalhospital of Pikine in Dakar]. Tunis Med. 2014;92(10):635638.

15. Lobo RA, Marcus R, Kelsey J. Menopause: Biology and Pathobiology. London: Academic press; 2000.

16. Wang F, Chen F, Huo X, et al. A neglected issue on sexual well-being following breast cancer diagnosis and treatment among Chinese women. PLoS One. 2013;8(9):e74473. doi:10.1371/journal.pone.0074473

17. Pinar G, Okdem S, Dogan N, Buyukgonenc L, Ayhan A. The effects of hysterectomy on body image, selfesteem, and marital adjustment in Turkish women with gynecologic cancer. Clin J Oncol Nurs. 2012;16(3):E99-104. doi:10.1188/12.cjon.e99-e104

18. Ilknur AA, Birsen A, Busra A. Evaluation of relationships, self-evaluation and self-esteem of women's with hysterectomy. Progress in Health Sciences. 2016 ;6(2):7-13.

19. Helstrom L, Lundberg PO, Sorbom D, Backstrom T. Sexuality after hysterectomy: a factor analysis of women's sexual lives before and after subtotal hysterectomy. Obstet Gynecol. 1993;81(3):357-362.

20. Mokate T, Wright C, Mander T. Hysterectomy and sexual function. J $\mathrm{Br}$ Menopause Soc. 2006;12(4):153-157. doi:10.1258/136218006779160607

21. Maas CP, Weijenborg PT, ter Kuile MM. The effect of hysterectomy on sexual functioning. Annu Rev Sex Res. 2003;14:83-113.

22. Roovers JWR, van der Bom JG, van der Vaart $\mathrm{CH}$, Heintz AP. Hysterectomy and sexual wellbeing: prospective observational study of vaginal hysterectomy, subtotal abdominal hysterectomy, and total abdominal 
hysterectomy. BMJ. 2003;327(7418):774-778. doi:10.1136/ bmj.327.7418.774

23. Bradford A, Meston C. Sexual outcomes and satisfaction with hysterectomy: influence of patient education. J Sex Med. 2007;4(1):106-114. doi:10.1111/j.1743-6109.2006.00384.x

24. Danesh M, Hamzehgardeshi Z, Moosazadeh M, ShabaniAsrami F. The Effect of Hysterectomy on Women's Sexual Function: a Narrative Review. Med Arch. 2015;69(6):387392. doi:10.5455/medarh.2015.69.387-392

25. Dragisic KG, Milad MP. Sexual functioning and patient expectations of sexual functioning after hysterectomy. Am J Obstet Gynecol. 2004;190(5):1416-1418. doi:10.1016/j. ajog.2004.01.070

26. Tozo IM, Moraes JC, Lima SM, et al. [Sexuality evaluation in women submitted to hysterectomy for the treatment of uterine leiomyoma]. Rev Bras Ginecol Obstet. 2009;31(10):503-507. doi:10.1590/S010072032009001000006

27. Salimena AM, Souza IE. o sentido da sexualidade de mulheres submetidas ahisterectomia: uma contribuição da enfermagem para aintegralidade da assistência ginecológica. Esc Anna Nery Rev Enferm. 2008;12(4):637-644.

28. Kain ZN, Sevarino F, Alexander GM, Pincus S, Mayes LC. Preoperative anxiety and postoperative pain in women undergoing hysterectomy. A repeated-measures design. J Psychosom Res. 2000;49(6):417-422.

29. de la Cruz CZ, Coulter ML, O’Rourke K, Amina Alio P, Daley EM, Mahan CS. Women's experiences, emotional responses, and perceptions of care after emergency peripartum hysterectomy: a qualitative survey of women from 6 months to 3 years postpartum. Birth. 2013;40(4):256263. doi:10.1111/birt.12070

30. Saini R, Saini S, Sharma S. Oral sex, oral health and orogenital infections. J Glob Infect Dis. 2010;2(1):57-62. doi:10.4103/0974-777x.59252

31. Hashemi S, Seddigh S, Tehrani FR, Khansari SM, Khodakarami N. Sexual behavior of married Iranian women, attending taleghani public health center. J Reprod Infertil. 2013;14(1):34-38.

32. Khajehaminian F, Ebrahimi M, Kamali M, Dolatshahi B, Younesi SJ. Sexual functioning after mastectomy surgeryA qualitative study. Iranian Quarterly Journal of Breast Diseases. 2014;7(3):50-58.

33. Kagawa-Singer M, Wellisch DK. Breast cancer patients' perceptions of their husbands' support in a cross-cultural context. Psychooncology. 2003;12(1):24-37. doi:10.1002/ pon.619

34. Pinar G, Okdem S, Dogan N, Buyukgonenc L, Ayhan A. The effects of hysterectomy on body image, selfesteem, and marital adjustment in Turkish women with gynecologic cancer. Clin J Oncol Nurs. 2012;16(3):E99-104. doi:10.1188/12.cjon.e99-e104

35. Reisy L LM, Hajizadeh I. The effect of abdominal hysterectomy procedure on quality of life and sexual function in women referred to Tehran teaching hospitals [dissertation]. Tehran: Tarbiat Modares University; 2011.

36. Gallicchio L, Harvey LA, Kjerulff KH. Fear of cancer among women undergoing hysterectomy for benign conditions. Psychosom Med. 2005;67(3):420-424. doi:10.1097/01. psy.0000160472.69303.56

37. Kim KH, Lee KA. Symptom experience in women after hysterectomy. Journal of Obstetric Gynecologic Neonatal Nursing. 2001;30(5):472-480. doi:10.1111/j.1552-6909.2001.tb01566.x

38. Janghorban R, Latifnejad Roudsari R, Taghipour A, Abbasi $\mathrm{M}$, Lottes I. The shadow of silence on the sexual rights of married Iranian women. Biomed Res Int. 2015;2015:520827. doi:10.1155/2015/520827

39. Griesser AC, Vlastos G, Morel L, Beaume C, Sappino AP, Haller G. Socio-demographic predictors of high support needs in newly diagnosed breast cancer patients. Eur J Cancer Care (Engl). 2011;20(4):466-474. doi:10.1111/ j.1365-2354.2010.01190.x

40. Hodgkinson K, Butow P, Hunt GE, Pendlebury S, Hobbs KM, Wain G. Breast cancer survivors' supportive care needs 2-10 years after diagnosis. Support Care Cancer. 2007;15(5):515-523. doi:10.1007/s00520-006-0170-2

41. Flory N, Bissonnette F, Binik YM. Psychosocial effects of hysterectomy: literature review. J Psychosom Res. 2005;59(3):117-129. doi:10.1016/j.jpsychores.2005.05.009

42. Johnson SM. The Contribution of Emotionally Focused Couples Therapy. J Contemp Psychother. 2007;37(1):47-52. doi:10.1007/s10879-006-9034-9

43. Alipour A., Yoosef Pour N. Effect of cognitive behavioral therapy in hastening recovery of women after hysterectomy surgery. J Behav Sci. 2010;4(2):3-4.

44. Cheung LH, Callaghan P, Chang AM. A controlled trial of psycho-educational interventions in preparing Chinese women for elective hysterectomy. Int J Nurs Stud. 2003;40(2):207-216.

Copyright $\odot 2018$ The Author (s); This is an open-access article distributed under the terms of the Creative Commons Attribution License (http://creativecommons.org/licenses/by/4.0), which permits unrestricted use, distribution, and reproduction in any medium, provided the original work is properly cited. 